SCientił studia, São Paulo, v. 9, n. 3, p. 527-61, 2011

\title{
âst \\ Formas de autonomia da ciência
}

\author{
Marcos Barbosa de Oliveira
}

\begin{abstract}
$\ddot{\sim}$
RESUMO

Na primeira parte deste ensaio, distinguimos três formas que a autonomia da ciência assume ao longo de sua história: a galileana, a vannevariana e a neoliberal. A galileana foi reivindicada por Galileu em seu conflito com a Igreja Católica. O termo "vannevariana" vem de Vannevar Bush, responsável pelo relatório Science, the endless frontier, que teve um papel fundamental na conformação das práticas científicas no período pós Segunda Guerra. A autonomia vannevariana diz respeito aos rumos da pesquisa científica. A autonomia neoliberal consiste na liberdade de cada cientista procurar financiamento para as pesquisas que deseja realizar em qualquer fonte, pública ou privada, tendo em vista apenas seu auto-interesse (intelectual e/ou econômico). Na segunda parte do ensaio, utilizamos o arcabouço conceitual e histórico proporcionado por essas distinções para discutir a questão: que forma de autonomia deve ser reivindicada pela ciência nos dias de hoje? O procedimento consiste em determinar, para cada uma das três formas, o que deve ser mantido e o que deve ser abandonado. A conclusão a que se chega é a de que a autonomia neoliberal deve ser descartada, a vannevariana restringida, e a galileana preservada.
\end{abstract}

PalaVras-chave • Autonomia da ciência. Galileu. Serendipidade. Neoliberalismo. Mercantilização. Inovação. Responsabilidade social da ciência. Éthos científico. Merton. Conflito de interesses.

\section{INTRODUÇÃO}

As recentes transformações no modo de produção do conhecimento científico recolocam em pauta, em um novo contexto, o tema da autonomia da ciência. Neste artigo procuramos dar uma contribuição ao debate distinguindo, na primeira parte, três formas que a autonomia da ciência assume ao longo da história. Na segunda parte, o objetivo é mostrar que essas formas constituem um arcabouço conceitual e histórico adequado para a procura de uma resposta à pergunta: que forma de autonomia deve ser reivindicada pela ciência nos dias de hoje? Deixamos em aberto a possibilidade de que a resposta seja: nenhuma. Optando por uma resposta afirmativa, esboçamos, com base nesse arcabouço, os traços mais marcantes da nova forma de autonomia a ser reivindicada. 


\section{A aUtonomia galileana}

A primeira forma de autonomia a ser considerada foi obra de Galileu. Para caracterizála, recorremos ao excelente estudo de Mariconda e Lacey "A águia e os estorninhos: Galileu e a autonomia da ciência" (cf. 2001).

Mariconda e Lacey (2001) principiam introduzindo a distinção entre fato e valor, enquanto fundamento da concepção de que a ciência é livre de valores. Segue-se uma exposição sucinta da análise desenvolvida por Lacey em vários de seus escritos, a qual identifica nessa concepção três componentes: a imparcialidade, a neutralidade e a autonomia. $\mathrm{O}$ foco é então dirigido à autonomia, e especialmente à contribuição de Galileu, oriunda de suas relações conflituosas com a Igreja Católica. Dizem os autores:

o símbolo de Galileu no conflito com a Igreja nutriu a ideia de que a ciência é ou deve ser livre de valores, permitindo que essa ideia ganhasse seu lugar como uma parte, reiteradamente afirmada e frequentemente reinterpretada, do auto-entendimento comum da tradição da ciência moderna. Mas quando se discute a liberdade da pesquisa científica, Galileu é muito mais que um símbolo; seus argumentos a favor da autonomia são seminais (Mariconda \& Lacey, 2001, p. 51, itálico no original).

Depois de algumas considerações, que identificam a autonomia reivindicada por Galileu com a liberdade de conduzir a investigação científica sem interferências, principalmente da Igreja Católica, secundariamente das autoridades acadêmicas, Mariconda e Lacey propõem uma reconstrução dos argumentos de Galileu a partir de três suposições: (1) A pesquisa científica realiza-se de acordo com determinados métodos, que envolvem observações, experimentos e inferências lógicas, mas não valores sociais. A ciência é imune a críticas provenientes de pontos de vista valorativos. (2) Tem autoridade para emitir juízos em nome da ciência apenas quem, sendo dotado das capacidades intelectuais e virtudes relevantes, segue rigorosamente as normas do método científico. (3) Os juízos científicos bem estabelecidos não têm implicação alguma para os domínios da teologia, da metafísica e dos valores (Mariconda \& Lacey, 2001, p. 52-3).

Com isso, encerra-se a primeira seção; nas três seguintes são discutidas as três suposições tais como figuram no pensamento de Galileu.

A primeira seção remete ao conceito laceyano de imparcialidade, e diz respeito ao método científico. Segundo os autores, embora as concepções metodológicas de Galileu, em contraste com as que vieram a consolidar-se como parte do auto-entendimento da ciência, pecassem por seu caráter apodítico, "ao apresentar seus argumentos em favor do sistema de Copérnico, Galileu mostra geralmente uma consciência sutil 
de alguns dos critérios não demonstrativos que devem informar a inferência científica correta" (Mariconda \& Lacey, 2001, p. $5^{3}$ ).

Como ilustração, são discutidos quatro de tais critérios: a adequação empírica, o poder explicativo, a limitação no uso de "ficções" e a simplicidade. O próximo passo consiste na identificação desses critérios com os valores cognitivos, distintos dos valores sociais e morais ou das crenças religiosas, sendo tal distinção o fundamento do conceito de imparcialidade.

Passando à segunda suposição, Mariconda e Lacey começam observando que "para Galileu, os juízos feitos de acordo com a imparcialidade proporcionam um conhecimento superior dos fenômenos naturais à luz de critérios que não trazem a marca de compromissos religiosos ou valorativos" (p. 56). Mas tal superioridade só pode prevalecer se for mantida a imparcialidade e, para que isso aconteça, é preciso que a ciência goze de autonomia.

Por outro lado, só fazem jus à autonomia os "especialistas", que cultivam o éthos científico, as virtudes do "espírito aberto e racional". Tal condição está relacionada com um argumento usado por Galileu em defesa do sistema copernicano, o argumento da "assimetria da conversão", que os autores discutem em considerável detalhe. Eles concluem a seção dizendo "basta, para nossos propósitos, lembrar que o argumento de Galileu em favor da autonomia depende de os cientistas quererem fazer juízos imparciais e cultivarem as virtudes geralmente necessárias para assegurar seu sucesso" (p. 59). O mesmo vale para os propósitos deste ensaio.

A terceira suposição pode ser interpretada como parte de um argumento cujo objetivo é estabelecer que a Igreja não tem motivos para interferir nas investigações científicas. Não tem motivos porque,

de acordo com Galileu, apesar das muitas aparências em contrário, seria impossível ocorrer um conflito epistêmico real entre os resultados científicos bem estabelecidos e as verdades religiosas (inclusive escriturais). A verdade, que é tomada por Galileu como sendo uma só, aponta para uma harmonia mútua, mas não para uma subordinação de um domínio ao outro.

Sempre que um resultado científico e uma passagem das Escrituras parecem estar em conflito, essa aparência de conflito pode ser removida por meio de reinterpretações apropriadas: ou o juízo científico foi inadequadamente confirmado ("demonstrado") ou a passagem escritural foi incorretamente interpretada (Mariconda \& Lacey, 2001, p. 59).

Para sustentar essas proposições, Galileu recorre ao argumento dos "dois livros". A ciência expõe o que está escrito no livro da natureza; a Igreja, o que está escrito no 
livro da revelação. "Esses livros, ambos de autoria divina, são escritos em linguagens diferentes. Usando (em grau significativo) categorias incomensuráveis, os livros servem a fins diferentes e precisam ser 'lidos' de maneira diferente; não podem ser traduzidos um ao outro. Portanto, nunca poderiam contradizer-se" (p. 6o).

Como diz Galileu, na famosa passagem sobre o "grandíssimo livro que continuamente nos está aberto diante dos olhos", a linguagem em que ele está escrito é a matemática, rigorosa, exata, e isenta de categorias de valor. Sendo assim, o argumento pode ser generalizado para todos os discursos referentes a valores, ou seja, a ciência é cognitivamente neutra no domínio dos valores.

Várias passagens de Mariconda e Lacey (2001) deixam claro que o interesse dos autores pelo tema não deriva de uma simples curiosidade histórica, mas principalmente de sua atualidade, de sua relevância para os problemas concretos que a ciência enfrenta nos dias de hoje. Assim, embora sustentando que "o argumento de Galileu refinado, generalizado e suplementado - permanece no centro de todas as defesas da autonomia da ciência" (p. 52), eles não deixam de trazer à tona (no segmento final do artigo), dois tópicos ausentes da discussão de Galileu no que se refere à autonomia, mas cruciais atualmente: o das aplicações do conhecimento científico, e o do financiamento das pesquisas.

A perspectiva que vamos esboçar a seguir diverge um tanto da de Mariconda e Lacey (2001), mas sem estar propriamente em contradição com ela. Em resumo, a ideia é a seguinte. Ao longo de seu desenvolvimento a partir do conflito com a Igreja, a ciência de fato conquistou a autonomia reivindicada por Galileu. Com exceção de alguns episódios isolados, conseguiu ver-se livre de interferências não apenas religiosas, mas também de outras naturezas. Por outro lado, em um momento histórico importante, em que se redefiniram as condições institucionais das práticas científicas, a saber, o do fim da Segunda Guerra, os tópicos ausentes da reivindicação de Galileu - as aplicações e o financiamento da pesquisa - entram em cena como elementos centrais no debate sobre a autonomia. Atuando conjuntamente, esses dois fatores fizeram com que a autonomia galileana passasse para o segundo plano, e uma nova forma de autonomia se constituísse, desempenhando o papel principal. Esta novidade é o tema da próxima seção. 


\section{A AUTONOMIA VANNEVARIANA ${ }^{1}$}

O documento que marca a entrada em cena da nova forma de autonomia é o relatório Science, the endless frontier (cf. Bush, 1990), preparado por Vannevar Bush a pedido do presidente Roosevelt, e entregue a seu sucessor, Truman, em julho de 1945. Atendendo à solicitação de Roosevelt, o relatório delineava as políticas científicas e tecnológicas a serem adotadas no país uma vez terminada a guerra, e foi muito influente, não somente nos Estados Unidos, mas em boa parte do mundo, na conformação das práticas científicas no período dos anos de ouro do século xx. ${ }^{2}$ Vamos chamar a ciência desse período de ciência dos anos de ouro (CAO), e de autonomia vannevariana a forma de autonomia que lhe é própria (não bushiana para evitar associações desagradáveis com George W. Bush). ${ }^{3}$

Foram duas as principais facetas da conjuntura que contribuíram para a emergência da autonomia vannevariana. De um lado, o prestígio conquistado pela ciência por conta de suas contribuições para o esforço de guerra, na forma de avanços no tratamento e na prevenção dos problemas de saúde dos combatentes, na invenção e aperfeiçoamento de dispositivos bélicos, especialmente o radar e, coroando o processo, a bomba atômica (lançada sobre Hiroshima um mês após a entrega do relatório a Truman). De outro lado, o aumento significativo do volume de recursos necessários para financiar a pesquisa, decorrente da crescente sofisticação das instalações, aparelhagens e materiais necessários, e da expansão do sistema. O que emergiu dessa conjuntura como proposta da comunidade científica, capitaneada por Bush, foi a de que o Estado deveria assumir a função de principal financiador da pesquisa, sendo essa alocação de recursos públicos legitimada pelos benefícios para toda a sociedade decorrentes das aplicações do conhecimento científico gerado.

Havia, contudo, um problema. Se o Estado financia a pesquisa, então, valendo o adágio he who pays the piper calls the tune (quem paga o flautista escolhe a música), ca-

1 A considerações a seguir baseiam-se em uma investigação atualmente em curso, da qual alguns resultados preliminares são expostos em Oliveira (no prelo).

2 Como evidência de quão marcante foi o relatório Bush, veja-se como se inicia a introdução de uma coletânea de textos comemorativos de seu cinquentenário: “a partir de sua publicação, em 1945, o relatório de Vannevar Bush (...) veio a adquirir um status bíblico na política científica. No dia em que veio à luz, foi saudado por manchetes de primeira página no New York Times. Desde então foi objeto de inúmeros ensaios, relatórios, análises e interpretações, estudado como se fosse a palavra de Deus, invocado para legitimar um amplo leque - às vezes contraditório de modelos de política científica, decisões e prioridades" (Cole et al., 2010, p. 1). Segundo Kitcher, "o documento mais importante sobre o lugar da pesquisa científica em uma democracia no século xx é certamente Science, the endless frontier, de Vannevar Bush" (Kitcher, 2001, p. 138)

3 A CAO corresponde, grosso modo, ao que Stokes (1997) denomina paradigma do pós-guerra, e Ziman (2000), ciência acadêmica. 
beria a ele o poder de decidir quais projetos de pesquisa devem ser empreendidos, quais não, em função do potencial de gerar aplicações práticas de cada um. Mas isso significa que, para contar com o financiamento do Estado, a ciência deveria abrir mão de sua autonomia, no que se refere ao direcionamento, aos rumos da pesquisa. Tratase de uma perspectiva que a comunidade científica, inserida em uma longa tradição, não via com bons olhos. A solução encontrada para o problema consistiu na mobilização de um certo argumento, baseado no que se pode chamar princípio da serendipidade.

Serendipidade (serendipity) é a faculdade de fazer descobertas interessantes por acaso, quando em busca de outra coisa. ${ }^{4}$ No caso da pesquisa científica, a ideia é a de que o objetivo é o avanço do conhecimento como um fim em si mesmo; o que se descobre depois, "serendipicamente", são as aplicações do conhecimento gerado. Em Bush (1990), os exemplos desse tipo de ocorrência na história da ciência são elevados a regra geral, resultando no princípio da serendipidade, ou seja, a proposição segundo a qual, entre as pesquisas científicas, não se pode prever quais vêm de fato a proporcionar aplicações, nem o tipo de problema prático que as aplicações contribuem para resolver, quando existem. Nos termos de Bush (1990):

uma das peculiaridades da ciência básica é a variedade de caminhos que levam ao avanço produtivo. Muitas das descobertas mais importantes resultaram de experimentos levados a cabo em função de propósitos muito diferentes. Estatisticamente, é certo que descobertas importantes e extremamente úteis resultarão de alguma fração dos empreendimentos na ciência básica; porém, os resultados de qualquer investigação em particular não podem ser acuradamente previstos (p. 18-9). 5

Tal imprevisibilidade naturalmente bloqueia a possibilidade de o Estado direcionar a pesquisa tendo em vista aplicações determinadas e, dessa forma, legitima a reivindicação de autonomia da ciência, no que se refere aos rumos da pesquisa. Escorada no princípio da serendipidade, a proposta defendida por Bush (1990) é a de que o

\footnotetext{
4. A palavra "serendipity" foi cunhada por Horace Walpole; figura em uma carta escrita por ele em 1754, em que menciona ter lido um conto de fadas chamado Os três príncipes de Serendip, cujos heróis eram dotados dessa faculdade. Serendip é um antigo nome de Sri Lanka (ex-Ceilão). Em 2006, foi publicado um livro póstumo de Robert Merton (em colaboração com Elinor Barber) inteiramente dedicado ao termo.

5 Em outra passagem, encontra-se a aplicação do princípio ao campo da medicina: "descobertas relevantes para o progresso da medicina vieram frequentemente de fontes remotas e inesperadas, e é certo que isso continuará a ser assim no futuro. É inteiramente provável que o progresso no tratamento das moléstias cardiovasculares e renais, do câncer e de moléstias refratárias semelhantes, venha a ser obtido como resultado de descobertas fundamentais em temas não relacionados a tais moléstias, e talvez totalmente inesperado pelo pesquisador" (Bush, 1990, p. 14).
} 
Estado deve limitar-se a prover um volume global de recursos para a pesquisa, ficando sua distribuição a cargo da própria comunidade científica, em função do interesse intelectual e da pura curiosidade de seus membros.

O progresso científico em um extenso campo resulta da livre atuação de intelectos livres, trabalhando em temas de sua própria escolha, ditados por sua curiosidade pela exploração do desconhecido. A liberdade de investigação precisa ser preservada em qualquer plano de apoio governamental à ciência (Bush, 1990, p. 12). ${ }^{6}$

Com base nesse relato sumário, podemos agora identificar as características da autonomia vannevariana, contrastando-a com a galileana. As interferências externas cuja possibilidade motiva a reivindicação da autonomia são, no caso da vannevariana, interferências do Estado, incidindo sobre os rumos da pesquisa; no caso da galileana, interferências da Igreja, incidindo sobre os métodos e o éthos da ciência. A natureza do poder de interferência também é diferente nos dois casos. No da autonomia galileana, o poder da Igreja é exercido, como dizem Mariconda e Lacey, "por meio de sua autoridade no ensino, de seu sistema legal de condenações e punições, pela coerção violenta ou pela ameaça de violência e por inúmeras outras formas de tormento" (Mariconda \& Lacey, 2001, p. 51). No caso vannevariano, o poder do Estado é econômico, é o poder de quem detém a chave do cofre. Quanto ao argumento mobilizado em defesa da reivindicação de autonomia, na galileana, como vimos, ele se apoia nas três suposições, referentes ao método, ao éthos, e à neutralidade cognitiva da ciência; na vannevariana, o fulcro é o princípio da serendipidade.

Há controvérsias sobre o grau em que a CAO gozou efetivamente da autonomia vannevariana (cf. Bush, 1990, p. xIx; Stokes, 1997, p. 2, 4, 50; Greenberg, 2001, cap. 3; Cole et al., 2010, p. 4). Porém, não há dúvida de que, ao longo das décadas seguintes, esse grau vai diminuindo, em um movimento histórico que continua vigoroso ainda nos dias de hoje. Tal movimento é o tema da próxima seção.

6 "O relatório de Bush foi magistral ao combinar duas perspectivas difíceis de conciliar. Por um lado, ele e os outros cientistas que trataram de aspectos específicos da organização da pesquisa insistiam em afirmar o valor da pesquisa para um amplo espectro de questões públicas. Por outro lado, eles queriam proteger a ciência de interferências e direcionamento externos, argumentando que a 'pesquisa básica' deveria ser livre, e receber 'proteção especial e apoio especialmente garantido"” (Kitcher, 2001, p. 138-9). 


\section{A PERDA DA AUTONOMIA VANNEVARIANA}

E O SURGIMENTO DA AUTONOMIA NEOLIBERAL

Em princípios da década de 1970, como se sabe, entra em crise o modelo de capitalismo do Estado de bem-estar social, associado, no plano da teoria econômica, às ideias de Keynes. Com a crise, tem início o movimento de ascensão e posterior hegemonização do neoliberalismo. Lançado por Friedrich Hayek (cf. 1977) em 1944 com a publicação de 0 caminho da servidão, o ideário neoliberal permanece em estado latente durante o período dos anos de ouro, ganha força na crise, e começa a ter suas políticas implementadas a partir da virada da década de 1970 para a de 1980 com as eleições de Margareth Thatcher no Reino Unido e Ronald Reagan nos Estados Unidos, que marcam o início do período neoliberal (cf. Harvey, 2007; Paulani, 2008; Anderson, 1996).

O neoliberalismo pode ser caracterizado, no que tem de mais essencial, como a fase do capitalismo em que se exacerba a propensão do sistema a transformar todas as categorias de bens em mercadorias (cf. Harvey, 2007, p. 165 ss). A maior parte das políticas neoliberais - incluindo a do Estado mínimo, com todas as suas implicações são decorrência direta do objetivo de promover a mercantilização universal, e isso vale também para as políticas científicas e tecnológicas (PCT). Tais políticas, associadas à difusão do ideário neoliberal na comunidade científica, e a outros fatores da conjuntura econômica, tiveram um impacto profundo nas práticas científicas, resultando no que vamos denominar ciência neoliberal. ${ }^{7}$

A mercantilização da ciência constitui um processo bastante complexo, que pode ser analisado em várias dimensões, como procuramos mostrar em um outro trabalho, já mencionado (cf. Oliveira, no prelo). No presente contexto, a dimensão relevante é aquela referente àquilo que está em jogo na autonomia vannevariana, ou seja, aos rumos da pesquisa científica. A ciência é mercantilizada nessa dimensão quando os rumos da pesquisa são ditados pelo mercado.

A principal estratégia do neoliberalismo para promover esse resultado pode-se chamar inovacionismo. Ela tem seu fulcro no conceito de inovação; consiste em postular a obtenção de inovações como objetivo primordial da pesquisa científica. O economista inglês Christopher Freeman $(1921-2010)^{\mathbf{8}}$ foi o autor que mais decisivamente contribuiu para a promoção do inovacionismo. Seu livro de 1974 teve uma influência enorme, não apenas no que se refere à inovação, mas também a outros aspectos fun-

7 A ciência neoliberal corresponde grosso modo à ciência pós-acadêmica de Ziman (2000), e à ciência no interesse privado de Krimsky (2003).

8 Sobre a vida e a obra de Freeman, uma boa introdução encontra-se nos obituários, e nos depoimentos de homenagem de seus inúmeros colegas e discípulos, dados a público depois de seu falecimento em agosto de 2010. O obituário da família, e links para vários outros estão acessíveis em <http://www.freemanchris.org/>. 
damentais da administração da pesquisa científica. Com as devidas ressalvas, pode-se considerá-lo emblemático da ciência neoliberal, desempenhando um papel análogo ao de Bush (1990) em relação à CAO. Embora o significado que tem hoje o conceito de inovação não fosse uma novidade na época (Freeman o credita a Schumpeter, como veremos), foi a partir da publicação de seu livro que ele começou efetivamente a difundir-se. No princípio lentamente, mas cerca de dez anos depois o processo acelera-se, com a introdução do conceito de sistemas nacionais de inovação, para o qual Freeman também deu uma contribuição fundamental (cf. Sharif, 2006, p. 750). E a partir da segunda metade da década de 1990 a inovação se estabelece como conceitochave nas PCT neoliberais, grosso modo, primeiro nos países centrais, depois nos periféricos; no Brasil, a partir do ano 2000 (cf. Cruz \& Chaimovich, 2010, p. 103-4; Carlotto, 2008, p. 98-112). Encontra-se em Freeman a definição do conceito que veio a tornar-se canônica:

devemos a Schumpeter a distinção extremamente importante entre invenções e inovações, que foi, desde então, em geral incorporada à teoria econômica. Uma invenção é uma ideia, um esboço ou um modelo para um novo ou aperfeiçoado dispositivo, produto, processo ou sistema. Tais invenções podem frequentemente (não sempre) ser patenteadas, porém não conduzem necessariamente a inovações técnicas. Na verdade, a maioria não faz isso. Uma inovação no sentido econômico é conseguida apenas com a primeira transação comercial envolvendo o novo produto, processo, sistema ou dispositivo, embora a palavra seja usada também para descrever o processo todo (Freeman, 1974, p. 22).

A ideia de inovação contrastada com a de invenção, e com ênfase no caráter comercial das aplicações, perpassa toda a literatura sobre o tema, figurando às vezes explícita, às vezes implicitamente (cf. Fagerberg, 2005; Dias \& Novaes, 2010). Ora, para realizar-se como aplicação comercial, uma invenção precisa ser rentável, precisa ser capaz de contribuir para a maximização dos lucros da empresa que lança um novo produto, ou adota um novo método de produção. Mas quem determina o que é rentável é o mercado. E sendo assim, na medida em que a obtenção de inovações torna-se o objetivo primordial da pesquisa científica, seus rumos passam a ser ditados pelo mercado. Com o avanço do inovacionismo, a ciência fica mercantilizada na dimensão em pauta, perdendo com isso sua autonomia vannevariana (cf. Garcia, 2010).

Assim como a CAO tem uma forma própria de autonomia, a vannevariana, a ciência neoliberal também tem a sua, a autonomia neoliberal. A autonomia neoliberal consiste na liberdade de cada cientista procurar financiamento para as pesquisas que deseja realizar em qualquer fonte, pública ou privada, tendo em vista apenas seu auto-inte- 
resse (intelectual e/ou econômico). O qualificativo justifica-se pelo viés individualista da concepção, próprio do capitalismo, e exacerbado, junto com a tendência mercantilizadora do sistema, no período neoliberal. 9

Em um contexto em que predomina o inovacionismo, as fontes públicas de financiamento também são direcionadas para a obtenção de invenções rentáveis e, sob essa luz, a autonomia neoliberal revela-se uma forma de operacionalizar o inovacionismo, de remover os obstáculos à vinculação da pesquisa aos interesses empresariais, para com isso colocar a determinação de seus rumos nas mãos do mercado.

No que se refere à argumentação legitimadora, a da autonomia neoliberal tem como premissa maior o princípio central do neoliberalismo, isto é, a tese da excelência do mercado enquanto sistema regulador da vida econômica. Embora a tese possa ser sustentada com base no argumento smithiano da mão invisível (em sua versão original, ou nas versões muito mais sofisticadas desenvolvidas pelos economistas ortodoxos), com a hegemonização do ideário neoliberal ela passa a funcionar à maneira de um dogma, de um pressuposto que dispensa uma fundamentação ou mesmo explicitação. Esse é o motivo pelo qual a argumentação legitimadora da autonomia neoliberal não costuma ser explicitamente posta por seus defensores ou, mais amplamente, pelos adeptos do inovacionismo; para eles, seria uma redundância.

Como anunciamos na introdução, na segunda parte deste artigo iremos delinear alguns traços da forma de autonomia que, segundo nossa proposta, deve ser reivindicada pela ciência. Com isso, mudamos o registro, de descritivo-analítico na primeira parte, para crítico nesta segunda. Observe-se que, para os adeptos do inovacionismo, a alegação de que a ciência está sendo mercantilizada não constitui absolutamente uma denúncia, ou um questionamento, muito pelo contrário, pois, sendo o dogma neoliberal pressuposto, é algo a ser celebrado.

Dada a mudança de registro, talvez convenha indicar desde já o lugar de onde falamos. Isso pode ser feito dizendo que o espírito que anima as considerações a seguir é o mesmo de certos autores e movimentos críticos da forma como a ciência e a tecnologia são praticadas nos dias de hoje, no contexto do sistema capitalista. Entre os autores, Lacey, Krimsky, Ziman, Testart, e outros; entre os movimentos, o Fórum Mundial Ciência e Democracia (FMCD), o Scientists for Global Responsibility (SGR), o International Network of Engineers and Scientists for Global Responsibility (INES), e a Fondation Sciences Citoyennes. ${ }^{10}$

9Aautonomia neoliberal corresponde essencialmente ao que Lacey (2008) denomina autonomia individualista moder$n a$, entendida como a "ausência de constrangimentos externos sobre as escolhas que os cientistas fazem para a realização de qualquer pesquisa que quiserem (no interior da abordagem descontextualizada), sob quaisquer fontes de recursos e sob quaisquer condições que escolherem aceitar (de modo consistente com a lei)" (Lacey, 2008, p. 316). 
Nosso procedimento consistirá em examinar, na ordem inversa, as três formas de autonomia, procurando determinar, para cada uma delas, o que deve ser mantido e o que deve ser abandonado.

\section{Descartando a aUtonomia neoliberal}

A crítica à autonomia neoliberal incide, naturalmente, sobre sua argumentação legitimadora, mas pode ser desenvolvida em diferentes níveis de generalidade. No mais alto, coloca-se em questão a tese da excelência do mercado ou, o que significa mais ou menos o mesmo, a validade do argumento da mão invisível, na sua forma geral, como se faz, por exemplo, na tradição marxista. Porém, no contexto do debate com os defensores do inovacionismo, e considerando o grau de hegemonia conquistado pelo ideário neoliberal, o mais adequado a nosso ver é uma crítica circunscrita aos domínios da ciência e da tecnologia, e interna, no sentido de recorrer ao mínimo a pressupostos e valores inaceitáveis pelos interlocutores. Ou seja, a estratégia deve consistir em confrontá-los em seus próprios termos, mostrando que, no campo da ciência e da tecnologia, a mão invisível é disfuncional, que os benefícios de sua atuação não são suficientes para compensar seus efeitos deletérios.

Uma crítica que exemplifica bem essa abordagem é a exposta em um relatório de Langley e Parkinson (2009), publicado no ano passado pelo SGR. ${ }^{11}$ Embora se concentre no Reino Unido, muito do que é dito aplica-se também, com as devidas ressalvas, a inúmeros outros países, dada a tendência à homogeneização das PCT, própria da globalização neoliberal. O objetivo do relatório é estudar as consequências nefastas da mercantilização da ciência e da tecnologia, pelo prisma das relações das universidades e institutos de pesquisa com as empresas privadas (as corporations). São estudados cinco setores: o da indústria farmacêutica, o da indústria do tabaco, o militar, o do petróleo e do gás e o da biotecnologia. Para cada setor, apresenta-se inicialmente uma descrição do pano de fundo, incluindo dados sobre sua dimensão econômica, listas das principais empresas que nele atuam, explicações sobre o modo de atuação, ligações que mantêm com as universidades etc. Vem a seguir uma exposição sobre as consequências nefastas dessas ligações, solidamente substanciada, com base, na maioria dos casos, em artigos publicados em revistas especializadas com revisão por pares, ou

10 Cf., respectivamente: 〈http://fm-sciences.org/?lang=pt>, 〈http://www.sgr.org.uk/frontpage>, <http://www.ines global.com/ines-home.phtml $>$, e $<$ http://sciencescitoyennes.org/ $>$.

11 O Documento Científico publicado neste número de Scientiae Studia é a tradução do Sumário Executivo do relatório em pauta. No texto introdutório ("O inovacionismo em questão"), discute-se o significado das teses do relatório do ponto de vista do Brasil. 
seja, de acordo com os critérios de certificação da própria ciência. As consequências são classificadas em quatro categorias, correspondentes às teses de que as ligações da ciência com o setor privado, em graus diferentes conforme o setor,

(1) influenciam a natureza da agenda de pesquisa, reduzindo seu âmbito;

(2) têm um impacto no direcionamento dos, e introduz tendenciosidade (bias) nos resultados de pesquisas específicas (tanto intencional quanto não-intencionalmente);

(3) comprometem a transparência das pesquisas (por exemplo, através de restrições comerciais de confidencialidade), e

(4) influenciam a interpretação pública dos resultados das pesquisas (por exemplo, por meio de lobbies) comprometendo potencialmente a percepção pública e a aceitação dos desenvolvimentos na ciência, na engenharia e na tecnologia (Langley \& Parkinson, 2009, p. 22).

Outra característica da crítica do SGR consiste em que não se limita a apontar os problemas, mas, em uma postura propositiva, aponta alternativas, providências concretas a serem tomadas para evitá-los. Da lista de dezesseis recomendações sugeridas, na versão que consta do Sumário Executivo do relatório, podem ser citadas, a título de ilustração, as seguintes:

- As universidades devem adotar padrões éticos mínimos para as companhias com as quais mantêm parcerias. Tais padrões devem incluir critérios sociais e ambientais, bem como acadêmicos, e devem ser supervisionados por um comitê especial.

- As universidades devem divulgar amplamente dados abrangentes sobre a natureza de suas parcerias com empresas.

- Todas as publicações acadêmicas devem desenvolver e implementar processos rigorosos para tratar de conflitos de interesse potenciais, inclusive sanções adequadas para o não cumprimento das normas estabelecidas.

- Mais pesquisa acadêmica precisa ser realizada a respeito dos efeitos deletérios potenciais da comercialização da ciência e tecnologia, especialmente nas universidades (p. 8).

Embora outras formas de questionamento sejam possíveis, e melhores, dependendo do tipo de interlocutor (por exemplo, os já imbuídos de uma visão crítica do capitalismo), quando se trata de argumentar com os adeptos do inovacionismo, a abordagem do relatório do SGR - dadas as características ressaltadas nesse rápido resumo, 
a saber, o caráter interno, a adoção de critérios científicos de certificação e a postura propositiva - é a nosso ver a mais adequada. É a que tem mais possibilidades de conseguir avanços na luta ideológica transformando-se no que realmente importa, em uma força material capaz de mudar a forma como a ciência e a tecnologia são praticadas. De um ponto de vista mais específico, acreditamos não haver melhor antídoto contra as acusações de obscurantismo e anticientificismo com que os representantes do establishment costumam desqualificar os críticos.

As razões para concluir que não é uma boa opção entregar a condução das práticas científicas ao mercado são também as razões para descartar a reivindicação da autonomia neoliberal.

\section{A AUTONOMIA VANNEVARIANA: RELATIVIZANDO O PRINGÍPIO DA SERENDIPIDADE E DEMOGRATIZANDO A CIÊNGIA}

Na periodização da história geral, entre os períodos dos anos de ouro e o neoliberal, localiza-se uma fase de transição, que tem lugar na década de 1970, e é marcada pela crise do Estado de bem-estar social. Na história da ciência, também faz sentido postular, ocorrendo na mesma época, uma fase de transição entre a CAO e a ciência neoliberal. No plano das ideias, essa fase se caracteriza pela emergência do conceito que vamos designar com o termo "pesquisa direcionada".

A linha de pensamento que conduz a tal conceito tem sua origem em um questionamento do princípio da serendipidade. A tese é a de que, motivada pelo anseio de autonomia, a comunidade científica teria exagerado na formulação do princípio, generalizando indevidamente os casos de serendipidade cuja existência é admitida. A demonstração é feita apontando contra-exemplos, ou seja, casos de pesquisas científicas bem-sucedidas, no sentido de que contribuíram para o avanço do conhecimento, mas empreendidas de antemão com vistas a determinadas aplicações. Também não há falta de casos deste tipo na história da ciência, como demonstra Stokes (cf. 1997). O exemplo exposto com considerável detalhe por Stokes como paradigma é o das pesquisas de Pasteur, feitas com o objetivo de aperfeiçoar os métodos de produção de vinagre, vinho e cerveja, de desenvolver métodos de prevenção de várias doenças etc., mas que também resultaram em contribuições importantes para o conhecimento a respeito do papel dos micro-organismos nos processos de fermentação e na etiologia das doenças infecciosas, conhecimento valioso como um fim em si mesmo, independentemente de qualquer aplicação.

A negação da validade universal do princípio da serendipidade torna possível que o Estado, em seu papel de financiador, leve em conta não apenas o potencial gené- 
rico de aplicação da pesquisa científica considerada em bloco, mas também o potencial específico de cada pesquisa, ou linha de pesquisa, associado a aplicações determinadas, previamente definidas. Quando isso ocorre, tem-se o que denominamos pesquisa direcionada. ${ }^{\mathbf{2}}$

Em seu livro, Stokes faz um levantamento das ocorrências dessa crítica no discurso sobre a política científica já a partir da década de 1950, mas é somente a partir da década de 1970, na fase de transição, que ela ganha força (impulsionada, no plano político, por uma relativa queda no prestígio da ciência). Observa-se nessas ocorrências uma intensa proliferação terminológica. Para o que chamamos de pesquisa direcionada, encontram-se (com nuances de significado) os termos "pesquisa programática", "pesquisa básica motivada”, "pesquisa básica orientada por missão”, "pesquisa básica orientada", "pesquisa estratégica" e "pesquisa básica inspirada pelo uso" (use inspired basic research, o termo adotado por Stokes, 1997, p. $\left.5^{8} \mathrm{ss}\right) .{ }^{13}$

Da maneira como foi definido, o conceito de pesquisa direcionada deixa em aberto aquilo que se põe como o objetivo da ciência, do qual devem decorrer os critérios usados pelo Estado na tomada de decisões sobre o financiamento. Uma possibilidade é que esse objetivo seja o neoliberal, de obter inovações, ou seja, - é bom lembrar - aplicações rentáveis. Dessa perspectiva, no plano conceitual, a pesquisa direcionada consiste claramente em um passo intermediário entre a pesquisa básica, não direcionada, e a pesquisa direcionada pelo mercado.

O fato de que o direcionamento da pesquisa pelo mercado é disfuncional não invalida a crítica ao princípio de serendipidade, ou seja, não constitui uma razão para rejeitar a ideia da pesquisa direcionada (sem eliminar a de pesquisa básica). Tudo depende das características do direcionamento, a saber, a que interesses responde, em que pressupostos se baseia, em quais estruturas institucionais são tomadas as decisões, que atores participam do processo etc.

Admitindo o princípio da justiça social, um requisito fundamental de uma ciência bem conduzida é que os resultados da pesquisa beneficiem equitativamente todos os grupos sociais. A satisfação do requisito depende dos interesses dos cidadãos, e deve-

12 A pesquisa direcionada não se confunde com a pesquisa aplicada, tal como concebida no relatório Bush. A pesquisa aplicada procura desenvolver aplicações de um conhecimento científico já existente, a direcionada busca novo conhecimento científico com potencial específico de aplicação.

13 Mais recentemente, Kitcher voltou à carga, criticando incisivamente o uso do princípio da serendipidade feito pelo relatório Bush, e tachando de elitista a forma de ciência que ele inspira. "A ênfase na serendipidade da descoberta, que vê os avanços científicos chegando por vias não previstas, dificilmente demonstra que aquilo que um grupo de cientistas considera tópicos ‘quentes' para a 'pesquisa básica' fornecerá os meios de satisfazer os desejos de um público mais amplo. Estritamente falando, tudo o que tais exemplos mostram é que a investigação pode levar a resultados inesperados, mas a conclusão que os autores almejam extrair é a de que um modo de escolher o rumo é particularmente propenso a ser auspicioso" (Kitcher, 2001, p. 14,1). 
se admitir também que o cidadão bem formado é quem melhor conhece seus interesses. Em uma ciência bem conduzida, portanto, os interesses dos cidadãos, tal como entendidos pelos próprios, devem ser levados na devida conta na determinação dos rumos da pesquisa. Em tese, a democracia representativa, nos moldes em vigor em boa parte dos países nos dias de hoje, seria capaz de dar conta do recado. Os cidadãos expressam seus interesses votando nos representantes que se propõem a defendê-los, orientando assim a ação do Estado na direção da justiça social. Há algumas décadas, entretanto, vem se firmando a constatação de que o modelo dominante de democracia - de maneira geral, não apenas no que se refere à ciência - não satisfaz o requisito, não leva na devida conta os interesses dos cidadãos. Essa constatação dá origem a movimentos em prol da democracia participativa, que promovem a instauração de formas de organização política no espírito da democracia direta.

No campo da ciência, o movimento se manifesta em iniciativas conhecidas coletivamente como conferências de cidadãos, embora o nome oficial em muitos casos seja diferente: "conferência de consenso", "júri de cidadãos" etc. Uma conferência de cidadãos trata de um setor determinado da tecnociência, sendo o dos OGM, o da nanotecnologia e o da energia nuclear os mais frequentes. Em linhas gerais, a atividade consiste em, primeiro, formar um grupo de leigos dispostos a participar, selecionados de acordo com metodologias desenvolvidas tendo em vista evitar a tendenciosidade. A seguir, em uma série de sessões, o grupo faz, por assim dizer, um curso rápido sobre o tema, com aulas dadas por especialistas e estudiosos, tendo a oportunidade de discutir com eles. E, por fim, debatem entre si as questões levantadas, e registram as conclusões a que chegaram. Esse relatório é então divulgado, na qualidade de indicador das posições e interesses da população, com o objetivo de fazer com que sejam considerados na definição das políticas para o setor (cf. Testart, 2002).

As conferências de cidadãos surgiram na década de 1970, nos Estados Unidos; em meados dos anos 1980 começaram a difundir-se na Europa e, a seguir, em outros continentes. Em Joss (cf. 2009) encontra-se um bom estudo, que envolve um histórico do fenômeno, considerações sobre o contexto histórico que explicam seu surgimento, uma análise de suas limitações, e sugestões de como superá-las. Para dar uma ideia a respeito das dimensões do processo, Joss menciona levantamentos segundo os quais, por exemplo, entre 1987 e 2002 foram realizadas 67 conferências, em 19 países; entre 2003 e 2009 , cerca de 70 conferências apenas sobre a nanotecnologia.

Os autores e os movimentos críticos mencionados acima são unânimes na defesa da democratização da ciência, e alguns expressam essa diretriz já em seu nome: Fórum Mundial Ciência e Democracia, Fondation Sciences Citoyennes. No plano teórico, merecem ser mencionadas as ideias de Kitcher (2001) em torno do conceito de ciência bem ordenada (well-ordered science), introduzido por ele. A ciência bem ordenada é, em es- 
sência, a ciência socialmente justa e democrática; o problema que Kitcher discute - de forma muito sofisticada, tomando como modelo as concepções de Rawls sobre a justiça - é o de saber quais são os processos adequados para a realização desses ideais, quais os papéis dos vários atores (os cientistas, o Estado, os cidadãos) nesses processos etc.

Um estudo mais aprofundado sobre os processos de democratização da ciência, na teoria ou na prática, extrapola os limites deste ensaio. Vamos limitar-nos a três observações, que versam sobre os valores da ciência, a responsabilidade social dos cientistas e a educação científica.

Uma reflexão sobre a maneira de conduzir a ciência deve levar em consideração, obviamente, seus objetivos, decorrentes dos valores que lhe são atribuídos, e que justificam a dedicação a ela. São essencialmente dois esses valores: o valor intrínseco, do conhecimento como um fim em si mesmo, próprio da ciência pura, e o valor instrumental, do conhecimento como meio de resolver problemas práticos, ou seja, como gerador de tecnologias.

Na concepção do relatório Bush, os dois valores manifestam-se de um modo peculiar, no qual o valor intrínseco só existe para o pesquisador, o valor instrumental só para a sociedade, representada pelo Estado. De acordo com o relatório, os rumos da pesquisa básica, ou pura, devem ser ditados apenas pela curiosidade intelectual dos pesquisadores, que além de não precisarem, também não devem, preocupar-se com as aplicações. A dissuasão justifica-se pela tese sustentada no relatório, segundo a qual a pesquisa aplicada rouba espaço da pesquisa básica.

É importante enfatizar a existência de uma lei perversa a governar a pesquisa. Sob pressão por resultados imediatos, e sem que políticas públicas sejam deliberadamente adotadas para evitar que isso aconteça, a pesquisa aplicada invariavelmente desaloja a pura. A moral é clara: é a pesquisa pura que merece proteção especial, e apoio especialmente seguro (Bush, 1990, p. 83).

Por outro lado, a única justificativa para a destinação de recursos públicos para o financiamento da pesquisa são os benefícios resultantes de suas aplicações, ou seja, é apenas o valor instrumental que importa. Embora a carta de encaminhamento do relatório faça referência ao "progresso cultural" (Bush, 1990, p. 2) e o Apêndice 3 (Relatório do Comitê de Ciência e Bem-Estar Público) diga que "é parte de nossas convicções democráticas a afirmação do valor cultural e estético intrínseco da tentativa do homem de fazer avançar as fronteiras do conhecimento e do entendimento" (p. 79), o que predomina é o valor instrumental. Como diz Stokes: 
Vannevar Bush julgava o recurso ao conhecimento como um fim em si mesmo tão insuficiente para a tarefa de sustentar o fluxo de apoio público para a ciência básica em tempos de paz que quase não o mencionou em seu relatório de quarenta páginas, um documento excelentemente afinado ao ouvido de sua audiência no pós-guerra. Em vez disso, Bush centrou sua argumentação no que se tornou a razão primordial para o apoio à pesquisa pura, a crença de que os avanços no entendimento obtidos pela pesquisa pura irão depois aperfeiçoar a condição humana (Stokes, 1997, p. 100; cf., também, Kitcher, 2001, p. 139).

Fica claro, portanto, que, na concepção do relatório, o valor intrínseco desempenha um papel secundário, restrito aos pesquisadores, reduzido a um meio para a realização do valor instrumental. Essa valorização do instrumental em detrimento do intrínseco, ou instrumentalização da ciência, constitui um processo mais amplo que o da mercantilização, e esteve presente também, na teoria e na prática, na União Soviética, e nos países que seguiram seu modelo de socialismo no século xx. O pressuposto, em qualquer caso, é que o cidadão comum, o não cientista, é um materialista vulgar, um pobre de espírito, incapaz de uma satisfação puramente intelectual. A instrumentalização da ciência parte logicamente desse pressuposto equivocado, mas ao instaurar-se tende a torná-lo verdadeiro. E, por isso, deve ser combatida, para fazer com que ela deixe de fomentar o empobrecimento espiritual da humanidade.

A revalorização do conhecimento como um fim em si mesmo permite que seja mantido o apoio público à pesquisa básica, não apenas em virtude de seu potencial gerador de aplicações, mas igualmente por seu valor intrínseco para os cidadãos. Desse ponto de vista, entretanto, deve ser levada em conta a inteligibilidade de cada contribuição para os não especialistas, da qual depende o número de pessoas aptas a desfrutarem a satisfação intelectual proporcionada por ela. Na decisão de quais projetos apoiar, o valor intrínseco deve ter um peso maior no caso de conhecimentos compreensíveis para os cidadãos, tais como os referentes à história da vida na Terra, especialmente a de nossa espécie, menor no caso de teorias abstrusas entendidas por um pequeníssimo número de especialistas, como a teoria das supercordas.

Outra consequência nefasta da instrumentalização é a tensão que ela introduz entre os órgãos financiadores da pesquisa e os pesquisadores, os quais, apesar de toda a pressão inovacionista mercantilizadora, ainda preservam a curiosidade, a paixão intelectual entre as motivações de seu trabalho. Essa tensão é o motivo que leva os cientistas a mentirem, exagerando o potencial tecnológico das pesquisas que propõem desenvolver, motivadas de fato apenas pelo interesse intelectual. Tais falsas promessas figuram tanto nos projetos de pesquisadores ou grupos de pesquisa, quanto em exercícios de relações públicas de setores da comunidade acadêmica com o objetivo de an- 
gariar o apoio da população à destinação de recursos para a realização de suas pesquisas. Como seres morais, os cientistas devem dar boas vindas a mudanças na concepção pública da ciência que restaurem seu valor intrínseco, podendo assim livrá-los da necessidade de mentir para ter condições de realizar-se em sua vocação.

Passando agora ao tópico da responsabilidade social, partimos do princípio de que, em qualquer processo democrático de condução das atividades científicas, os cientistas devem desempenhar um papel imprescindível, por serem os detentores do conhecimento especializado necessário para informar a tomada de decisões (por exemplo, relacionando as alternativas tecnicamente viáveis para a superação de cada problema). Além disso, assim como qualquer outro grupo social, e mais ainda por serem os produtores diretos do conhecimento científico, os cientistas têm o direito de lutar por seus próprios interesses (desde que, evidentemente, não ignorem os interesses de outros grupos sociais, incorrendo na prática do corporativismo). Entretanto, para que o diálogo com os outros atores seja profícuo, é necessário que, além de dominar os conhecimento próprios das respectivas especialidades, os cientistas tenham a formação necessária para refletir seriamente sobre os impactos das aplicações desses conhecimentos na sociedade ou, mais amplamente, sobre o significado social de seu trabalho. Ter consciência desse significado e levá-lo na devida conta equivale, em uma definição negativa, a não ser alienado (em um dos sentidos do termo na tradição marxista), em uma definição positiva, ao exercício da responsabilidade social.

Com essa designação, o tema da responsabilidade social da ciência eclodiu na esteira das bombas atômicas lançadas sobre Hiroshima e Nagasaki (cf. Barber, 1952, p. 225 ss). Desempenhou inicialmente um papel importante nos debates, mas depois foi perdendo a força, só vindo a revigorar-se em fins da década de 1960, no contexto das mobilizações em torno da guerra do Vietnã. É dessa época a fundação, em 1969, da British Society for Social Responsibility in Science (cf. Rose \& Rose, 1976). Com a ascensão do neoliberalismo, o tema entra em baixa de novo, praticamente sai de cena, até, mais recentemente, ser recuperado pelos movimentos e autores críticos da ciência neoliberal. Constituindo uma espécie de corolário da tese da democratização da ciência, e sendo a autonomia neoliberal sua antítese, o princípio da responsabilidade social é também uma unanimidade nos movimentos (figurando no nome do SGR).

Entre os autores, Ziman trata longamente do tema, particularmente em dois artigos incluídos na coletânea de Ziman (cf. 1995a, 1995b). No primeiro artigo, Ziman critica os cientistas, que "pela sua formação deveriam ser indivíduos altamente responsáveis, fortemente orientados para o bem comum", dizendo que "esses mais refinados representantes de nossa civilização parecem às vezes carecer da mais elementar sensibilidade das pessoas civilizadas, da consideração para com os sentimentos e necessidades de seus compatriotas" (Ziman, 1995a, p. 181). Examinando as racionaliza- 
ções de que se valem os cientistas para eximir-se de sua responsabilidade social, Ziman apresenta uma lista de 13 teses em que elas se baseiam, por exemplo, "toda ciência é boa ciência", "a ciência é racional e objetiva", "a ciência é neutra" etc.

Kitcher (cf. 2001) e Lacey (cf. 2008) também dedicam bastante atenção ao tema. A incompatibilidade entre a reivindicação da autonomia neoliberal e o descompromisso com a responsabilidade social é assim exposta por Lacey:

os cientistas podem exercer corretamente suas responsabilidades, enquanto cidadãos democráticos, com a condição de exercerem primeiramente suas responsabilidades enquanto cientistas, e isso é favorecido pela sustentação de valores éticos e sociais que contrariam aqueles que são fornecidos pela ciência de interesse privado, na qual (ao tratar de questões de legitimidade) os valores tradicionais da ciência estão subordinados aos valores do capital e do mercado. Os cientistas engajados na ciência de interesse privado tendem a não exercer corretamente suas responsabilidades e, consequentemente, não pode haver, em princípio, forte objeção, fundada na "autonomia" da ciência, contra cidadãos que reivindicam uma função na direção, no monitoramento e na avaliação dos projetos científicos e também na determinação das prioridades para o financiamento público na pesquisa, em vista de propósitos democráticos (Lacey, 2008, p. 323).

Para exercer a responsabilidade social, não basta a vontade, é necessário que os cientistas tenham as condições que viabilizem essa prática. Uma reflexão séria sobre o significado do próprio trabalho exige dedicação, não é algo que possa ser feito apenas nas horas vagas. Pressupõe certa familiaridade com as grandes linhas de pensamento das humanidades e ciências sociais, requer tempo e energia intelectual para leituras, reflexões e diálogos. Ora, como procuramos mostrar em Oliveira (2008), uma das consequências do produtivismo associado à taylorização, que vem sendo imposta pelo neoliberalismo ao regime de trabalho dos pesquisadores, é privá-los desse tempo e dessa energia. Reflexões envolvidas no exercício da responsabilidade social, mesmo que resultem em publicações, não são em geral publicáveis em revistas especializadas, como contribuições para o avanço do conhecimento científico. Sendo assim, não contam pontos no currículo do pesquisador, segundo as normas da avaliação neoliberal. O tempo e a energia gastos em tal tipo de reflexão aparecem, portanto, nessa perspectiva, como tempo e energia roubados do trabalho realmente produtivo.

Afirmamos acima, com relação à ciência, que o cidadão bem formado é quem melhor conhece seus interesses. A razão para o qualificativo consiste em que para ter efetivamente essa consciência, o cidadão precisa ter um mínimo de familiaridade com a ciência, e com o impacto de suas aplicações na sociedade, além naturalmente do es- 
pírito crítico, da capacidade de pensar com a própria cabeça. A implicação disso para a educação científica - tanto a fundamental, de todos, quanto a superior, dos futuros cientistas, para serem capazes de exercer a responsabilidade social - deve envolver não apenas o ensino de ciências, mas também sobre as ciências. Isso significa, na prática, a introdução nos currículos de temas da filosofia, da história e da sociologia da ciência, e a realização de debates sobre as questões mais candentes, como a dos OGM e a das mudanças climáticas. Há inúmeros movimentos no mundo todo que se pautam por esses princípios (cf. Ziman, 1980, 1984; Matthews, 1994; Höttecke \& Silva, 2011).

Essas considerações dão uma medida de quão profundas devem ser as mudanças nas políticas científicas e tecnológicas, na mentalidade e nas atividades dos cientistas, e na educação científica, para que se realize o ideal de uma ciência bem-conduzida.

\section{A AUtonomia GALILEANA: PRESERVANDo A OBJETIVIDADE DA GIÊNGIA}

Ao descrever os processos que levaram ao surgimento da autonomia neoliberal, concentramos a atenção no solapamento da autonomia vannevariana por eles promovido. Veremos agora que eles ameaçam também a autonomia galileana, na medida em que promovem violações das normas do éthos científico, minando, assim, a objetividade da ciência. O roteiro desta seção é o seguinte. Começamos com uma rápida exposição sobre o éthos científico (daqui por diante, simplesmente éthos), centrada nas contribuições pioneiras de Merton sobre o tema. Em seguida, apresentamos as violações do éthos promovidas pela mercantilização, e apontamos suas consequência nefastas, deixando claro por que é imprescindível evitar que ocorram ou, em outras palavras, por que a autonomia galileana precisa ser preservada. O segmento final tem como fio condutor o desenrolar da fortuna crítica das concepções mertonianas sobre o éthos, e como objetivos discutir o significado e a validade de suas normas, e situar as atuais violações em uma perspectiva histórica mais ampla.

O conceito de éthos foi introduzido por Merton em 1938 (Merton, 1973a [1938]) de forma ainda rudimentar, e desenvolvido em 19422 (Merton,1973b [1942]). ${ }^{14}$ O éthos

14 O artigo de 1938 saiu originalmente em Philosophy of Science, vol. 5; o de 1942 no Journal of Legal and Political Sociology, vol. 1. Ambos foram reproduzidos nas coletâneas Social theory and social structure (Merton, 1949) e The sociology of science (Merton, 1973), que foi utilizada como fonte das citações a seguir no texto. O artigo de 1942 foi incluído também em Sociology of science: selected readings (Barnes, 1972). Em cada uma de suas publicações, saiu com um título diferente. Na original, "A note on science and democracy"; em Merton (1949), "Science and democratic social structure"; em Barnes (1972), "The institutional imperatives of science"; em Merton (1973), "The normative structure of science". Para complicar ainda mais a situação, na literatura secundária, encontra-se "Science and technology in a democratic order" como título da publicação de 1942 (cf. Barnes, 1972, p. 65; Shinn \& Ragouet, 2008, p. 199; Garcia e Martins, 2009, p. 103, bem como a nota de rodapé na p. 267 de Merton, 1973). 
é identificado com o "complexo emocionalmente tonalizado de valores e normas considerado obrigatório para o cientista. As normas são expressas na forma de prescrições, proscrições, preferências e permissões", e legitimadas em termos de valores institucionais (Merton, 1973b [1942], p. 268-9). Têm duas facetas: são, ao mesmo tempo, normas éticas e normas "técnicas". Enquanto normas éticas, estão associadas, no plano institucional, aos valores da ciência, no plano pessoal, aos valores e sentimentos dos cientistas, sendo transmitidas por preceito e exemplo, reforçadas por sanções, e internalizadas em grau maior ou menor pelos cientistas. Enquanto normas técnicas, indicam o meio, ou o caminho para a realização da meta institucional da ciência, a extensão do conhecimento certificado. Este último é o conhecimento objetivo, confiável como um guia para a ação, e capaz de gerar aplicações eficazes.

Talvez por receio de atolar no terreno pantanoso das controvérsias epistemológicas sobre o método científico, Merton trata rapidamente do tema, justificando-se com a afirmação de que seu artigo "é um ensaio na sociologia da ciência, não uma digressão sobre a metodologia” (Merton, 1973b [1942], p. 268). Entretanto, na estrutura teórica em que o éthos se insere, o método desempenha um papel fundamental. Do ponto de vista lógico, ele vem em primeiro lugar. As normas do éthos pressupõem os princípios metodológicos, sua função é fazer com que eles sejam efetivamente aplicados, de modo a preservar a objetividade do conhecimento científico. Na análise de Mariconda e Lacey, a relação entre o método e o éthos é a mesma: primeiro o método, depois o éthos (uma das implicações dessa ordem será trazida à tona na conclusão).

As normas distribuem-se em quatro categorias, designadas com os termos universalismo, comunismo, ${ }^{\mathbf{1 5}}$ desinteresse, e ceticismo organizado. Muito sucintamente, o universalismo corresponde à ideia de que "a objetividade exclui o particularismo", e, assim, a certificação do conhecimento científico não deve envolver critérios religiosos, raciais, étnicos, políticos, de nacionalidade, classe, gênero etc. O comunismo é o princípio da ciência como patrimônio comum da humanidade. Na terminologia dos direitos de propriedade intelectual, o princípio implica que o autor de uma contribuição tem sobre ela direitos morais (ligados ao reconhecimento), mas não direitos patrimoniais (os que proporcionam vantagens monetárias). O comunismo impõe ao cientista o dever de publicar suas descobertas, e opõe-se à confidencialidade. A norma do desinteresse não implica que o cientista não tenha interesses (além, é claro, do interesse intelectual, perfeitamente legítimo), mas que aja como se não os tivesse, isto é, não permitindo que eles desviem a pesquisa do caminho da objetividade. O ceticismo organizado é a prescrição da atitude crítica, da não aceitação de afirmações sem o devi-

15 Barber (1952) substituiu communism por communalism, por motivos decorrentes do macarthismo reinante nos Estados Unidos (cf. Merton \& Barber, 2006, p. 295, nota115). Uma boa parte da literatura posterior incorporou essa mudança terminológica. 
do exame segundo critérios lógicos e empíricos. Opõe-se à credulidade e ao dogmatismo, não admitindo a existência de afirmações que não possam ou não devam ser colocadas em dúvida (Merton, 1973b [1942], p. 268-70). ${ }^{16}$

Isso posto, passamos a apresentar os casos de violação das normas do éthos fomentados pela mercantilização da ciência. Eles ocorrem principalmente no campo das pesquisas relacionadas às mudanças climáticas e no da biomedicina e, dentro deste, em particular, no setor da produção de medicamentos.

O que está em jogo no campo das mudanças climáticas é o conflito entre o interesse da humanidade toda, e o das empresas de petróleo e gás, que veem ameaçada sua lucratividade pelo imperativo de restringir o uso de combustíveis fósseis. A estratégia das empresas consiste em fomentar o ceticismo do clima, o colocar em dúvida a existência de mudanças climáticas significativas, seu caráter antropogênico, ou seu impacto para os seres humanos. Essa manobra é facilitada pela incerteza inerente às conclusões das pesquisas científicas nesse campo, que são entretanto grandemente exageradas. Na prática, a atuação das empresas consiste em financiar think tanks, ou seja, grupos de investigação e propaganda extra-acadêmicos, que se apresentam como científicos, mas violam deliberadamente a norma do desinteresse, distorcendo as evidências, ou sua interpretação, tendo em vista os interesses de seus financiadores (cf. Langley \& Parkinson, 2009; Pittock, 2009).

Entre as várias maneiras de lidar com as questões de saúde - incluindo a da medicina preventiva, voltada para o estudo das causas das doenças decorrentes do estilo de vida, da alimentação, das condições ambientais, do saneamento etc. - a mais rentável é a via medicamentosa, explorada pela indústria farmacêutica. A implicação disso, no contexto do processo de mercantilização da ciência, é o desfavorecimento das pesquisas na abordagem preventiva. Esta, porém, é uma consequência nefasta que diz respeito ao rumo da pesquisa, e o que nos interessa agora é o impacto da mercantilização sobre o éthos. ${ }^{17}$ São cruciais para a lucratividade das empresas farmacêuticas as pes-

16 Alguns comentadores acrescentaram outros itens à lista de Merton, como a originalidade e o individualismo. Invertendo a ordem dos dois primeiros itens, e inserindo a originalidade entre o desinteresse e o ceticismo organizado, Ziman ilustra e procura mostrar a plausibilidade das normas do éthos, em uma passagem bem sugestiva: "a virtude particular das normas de Merton reside em que elas enfatizam as práticas e princípios que afetam diretamente os indivíduos e que genuinamente distinguem a ciência de outras instituições e vocações. Parece de fato ser tão importante quanto verdadeiro que os cientistas normalmente não se comportam como espiões (treinados para manter secretas suas ações), nem como membros de uma seita religiosa (que devem aceitar a autoridade de seu guru), nem como lojistas (que ganham a vida anunciando suas mercadorias), nem como antiquários (cujos bens mais valiosos são velhos e de segunda mão), nem como soldados (cujo dever é não perguntar por que). A cultura da ciência é caracterizada e estruturada precisamente por tais diferenças" (Ziman, 2000, p. 33).

$\mathbf{1 7}_{7}$ Outras duas consequências nefastas para os rumos da pesquisa são os problemas das doenças negligenciadas e da fabricação de doenças (disease mongering). As doenças negligenciadas são as que ocorrem predominantemente em países pobres, e recebem uma proporção diminuta dos recursos para a pesquisa, uma vez que os medicamentos que 
quisas sobre a qualidade dos medicamentos produzidos, sobre sua eficácia (em que medida têm os efeitos terapêuticos que deles se esperam), e sobre seus efeitos colaterais, especialmente os negativos. As violações do éthos nesse terreno têm por objetivo distorcer os resultados das pesquisas, ou sua divulgação, exagerando a eficácia dos medicamentos, e minimizando, ou ocultando, seus efeitos colaterais negativos (cf. Brown, 2010; Resnick, 2010; Musschenga et al., 2010).

A tendenciosidade (bias) das pesquisas de avaliação de medicamentos tem vindo à tona com grande intensidade nos últimos tempos, frequentemente na forma de escândalos. Esse fenômeno provoca uma reação da comunidade científica, que gera um amplo debate em torno da noção de conflito de interesses (obviamente relacionada à norma mertoniana do desinteresse). Um pressuposto do debate é o de que, sendo declarados os interesses econômicos dos pesquisadores e financiadores de uma pesquisa quando da divulgação de seus resultados, a tendenciosidade pode ser detectada com mais facilidade, e assim desencorajada. Krimsky discute extensa e rigorosamente essa questão, concluindo que regras mais estritas sobre declarações de interesse não são suficientes para resolver o problema (cf. Krimsky, 2003, cap. 8-10). ${ }^{\mathbf{8}}$

Ao discorrer sobre o comunismo em 1942, Merton já apontava o conflito existente entre essa norma e a instituição dos direitos de propriedade intelectual (DPI), especialmente as patentes. Nas últimas décadas, o impacto dos DPI sobre as pesquisas tecnocientíficas adquiriu dimensões incomparavelmente maiores. Muito resumidamente, a partir da década de 1980, enquanto uma faceta do processo de ascensão do neoliberalismo, articula-se uma ofensiva dos DPI, liderada pelos Estados Unidos, com a colaboração de outros países centrais do sistema capitalista. O objetivo era ampliar e fortalecer os DPI, em particular impondo a todos os países, ricos e pobres, padrões mínimos para a legislação dos DPI de cada país. O marco mais importante nessa ofensiva, que ainda está em curso, foi a assinatura em 1994 do Acordo sobre os Aspectos Rela-

resultariam das pesquisas não seriam rentáveis, dado o baixo poder aquisitivo das populações afetadas. Na vasta literatura sobre o tema, é frequente a referência à "falha (gap) 10/90": 90\% dos recursos para pesquisa vão para as doenças dos países ricos, onde mora 10\% da população da Terra; 10\% para as doenças dos países pobres, onde mora 90\% da população. Em um dossiê da revista Nature, encontra-se o seguinte dado: dos 1223 medicamentos desenvolvidos entre 1975 e 2007, apenas 13 foram para doenças negligenciadas (cf. Butler, 2007, p. 158). A fabricação de doenças consiste na transformação em doenças de características de uma pessoa vistas tradicionalmente como traços de personalidade, por exemplo, a timidez, que vira "transtorno da ansiedade social"; o comportamento inquieto, que vira "transtorno de déficit de atenção e hiperatividade" (TDAH), ou então, a redução do nível de alguma grandeza medida em exames clínicos, tal como o nível de colesterol no sangue, acima do qual se considera necessário o uso de medicamentos (cf. Moynihan et al., 2006; Applbaum, 2009).

18 Como deve ter ficado claro pelo contexto, neste ensaio o termo "ciência" é usado com o sentido de "ciências naturais". No domínio das ciências humanas, uma área em que os desvios da objetividade causados pela interferência de valores econômicos têm ocorrido de forma nada menos que escandalosa é a da Economia, como se vê claramente no documentário "Trabalho interno" (Inside job), a respeito da crise de 2008. 
cionados ao Comércio dos Direitos de Propriedade Intelectual, conhecido internacionalmente pela sigla TRIPS (de Agreement on Trade Related Aspects of Intellectual Property Rights). O TRIPS foi um dos dois resultados mais importantes da Rodada do Uruguai do GATT (General Agreement on Tariffs and Trade). O outro foi a transformação do GATT, criado logo após o fim da Segunda Guerra, na OMC (Organização Mundial do Comércio). Segundo muitos especialistas, o TRIPS favorece os interesses dos países centrais em detrimento dos periféricos, tendendo assim a aumentar a brecha econômica entre os dois grupos. ${ }^{19}$ No que se refere à indústria farmacêutica, o TRIPS teve um papel absolutamente crucial, uma vez que em muitos países, inclusive o Brasil, os medicamentos não eram patenteáveis; passaram a sê-lo para serem cumpridas as obrigações assumidas com a assinatura do acordo. ${ }^{20}$

As metas de, por um lado, conseguir ganhos monetários por meio da obtenção de patentes, por outro, de ocultar resultados desfavoráveis de pesquisas levam à imposição de normas de confidencialidade, violando assim outra das facetas do comunismo.

Entre as práticas da indústria farmacêutica, encontram-se ainda muitas em desacordo com princípios ainda mais básicos de honestidade. Uma lista exaustiva seria longa demais para ser exposta aqui. Elas vão desde a prática, muito difundida, do ghost writing, na qual pesquisadores renomados, em troca de vantagens monetárias, assinam como se fossem autores de artigos escritos por funcionários das empresas farmacêuticas (cf. Krimsky, 2003, p. 115 ss; Langley \& Parkinson, 2009, p. 26), até a produção de revistas pseudo-científicas, isto é, que se apresentam como se seguissem as normas da revisão por pares, mas que, na verdade, são veículos de propaganda das empresas que as financiam (cf. Grant, 2009a, 2009b).

19 Para uma excelente análise, muito minuciosa e bem fundamentada, do processo que culminou na assinatura do TRIPS, ver Drahos \& Braithwaite (2003). Ver também Gontijo (2003, 2005). Uma das principais manobras da ofensiva foi a transferência do papel de órgão de discussão e deliberação sobre os DPI, em nível internacional, da Organização Mundial da Propriedade Intelectual (OMPI) para a OMC. Na OMPI, uma agência da ONU, vigora nas votações o princípio igualitário segundo o qual cada país tem direito a um voto, todos com o mesmo peso. Na OMC, cada voto tem um peso, proporcional às dimensões econômicas do país, o que naturalmente favorece os países centrais, especialmente os Estados Unidos, em detrimento dos países periféricos.

20 Para críticas ao sistema dos DPI, e propostas de formas alternativas de prover recursos para as atividades de criação, no terreno da cultura, e da pesquisa, no caso da tecnologia (especialmente para a pesquisa relacionada aos medicamentos), ver Stiglitz (2008) e Baker (2005). O impacto dos DPI sobre o éthos é estudado por Belt (2010) e Radder (2010), que expõem o impacto negativo das patentes em outras normas mertonianas, além do comunismo. Sterckx (2010) trata das consequências perniciosas das patentes no campo da pesquisa acadêmica. No setor de medicamentos, o sistema de patentes tem outra consequência nefasta referente aos rumos da pesquisa, a saber, a dos medicamentos de imitação (me too drugs) - criados para substituir medicamentos cujo prazo de validade está em vias de expirar, tendo o medicamento de imitação (protegido por nova patente) qualidade igual ou, muitas vezes, inferior à do medicamento imitado (Angell, 2004, cap. 5; Brown, 2010). Do ponto de vista da sociedade, é obviamente um desperdício o gasto de recursos com pesquisas visando medicamentos de imitação. 
As consequências nefastas da violação das normas do éthos no campo da biomedicina incluem as específicas, mais precisas, como, por exemplo, a morte de pacientes em decorrência de efeitos colaterais de medicamentos tomados, sendo esses efeitos conhecidos, mas ocultados pelas empresas produtoras. Mas encontra-se também uma consequência mais difusa, cumulativa, alimentada especialmente pelos escândalos que chegam à grande imprensa, que consiste na perda de autoridade da ciência, isto é, a degradação da percepção pública da ciência, que deixa de ser vista como fonte de conhecimento confiável. Essa autoridade é crucial especialmente em se tratando de problemas que só podem ser superados com a colaboração dos cidadãos, como, por exemplo, o da dengue. Se a população não acredita na teoria científica segundo a qual a doença é causada por um vírus transmitido pelo Aedes aegypti, não tem razões para participar da campanha de eliminação dos criadouros desses mosquitos. Como na fábula do menino e o lobo, um alerta lançado pela ciência (por exemplo, sobre a necessidade de a população tomar uma determinada vacina) pode ter consequências trágicas (a ocorrência de uma epidemia), se for ignorado devido à perda de autoridade da ciência.

Mesmo constatando que a ciência é corresponsável pelos grandes problemas que a humanidade enfrenta, especialmente os ambientais, é difícil imaginar que sua superação possa dar-se sem o recurso ao conhecimento científico. Basta considerar que a própria detecção de alguns dos problemas - incluindo o do buraco na camada de ozônio, o do aquecimento global e o do impacto das várias formas de poluição na saúde humana - são resultados da pesquisa científica. Como dizem o FMCD e o SGR em suas plataformas, a ciência é parte do problema, mas também parte da solução. Mas para poder dar a contribuição que dele se espera, o conhecimento científico deve ser confiável, eficiente como guia para a ação, capaz de gerar aplicações eficazes e passível de ser aceito como tal pela população. Mas, para isso, é preciso que ele seja objetivo, e para ser objetivo, é necessário que as normas do éthos sejam obedecidas. Ou, em outras palavras, que a autonomia galileana seja preservada.

Passando agora ao último item de nosso roteiro, consideremos a fortuna crítica das concepções mertonianas sobre o tema. Os dois artigos de Merton, de 1938 e 1942, demoraram um pouco para repercutir. Em um primeiro período, suas ideias foram bem recebidas, em trabalhos de seguidores seus, como Barber (1952) e Storer (1966) (cf. Stores apud Merton, 1973c, p. xx, 227). Um pouco mais tarde, passam a ser incisivamente contestadas por pioneiros da vertente construtivista pós-moderna na sociologia da ciência, que começava a formar-se na época, entre os quais Mulkay (1969), Barnes \& Dolby (1970), West (1972) e Mitroff (1974). Uma discussão detalhada sobre esses questionamentos está além dos limites deste ensaio (cf. Radder, 2010a; Cupani, 1998; Toren, 1983). Diremos apenas que a nosso ver de maneira geral eles pecam por interpretar as concepções de Merton enquanto contribuições à sociologia da ciência, con- 
cebida em moldes naturalistas, como uma disciplina factual, descritiva e explicativa, mas não normativa ou prescritiva, em outras palavras, isenta de juízos de valor sobre o objeto da investigação. Algumas das objeções parecem mesmo ignorar a natureza essencial de uma norma, que, enquanto tal, não é invalidada pelo fato de não ser sempre obedecida. Além disso, a crítica tem algo de paradoxal - uma falha de reflexividade ou, na visão de Kalleberg (200ךb, p.151-2), uma “contradição performativa”, dado que a própria ação de seus autores ao empreender investigações sobre o tema, desenvolvêlas e publicar seus resultados da maneira como o fizeram, é, em uma interpretação bastante plausível, decorrência da aplicação das normas mertonianas. A argumentação impessoal mobilizada na defesa de suas teses, isenta de referências a nacionalidades, etnias, religiões etc., e envolvendo menção a evidências empíricas, pode ser usada para ilustrar a norma do universalismo; a publicação dos estudos, a do comunismo; o fato de seus escritos não fazerem menção a interesses não cognitivos, a do desinteresse; e o colocar em questão as teses de Merton, a do ceticismo organizado. Os sociólogos da ciência críticos de Merton não podem, portanto, justificar seus próprios trabalhos sem recorrer ao éthos cuja validade contestam. São hipócritas às avessas, pautam conscienciosamente sua conduta por preceitos que alegam não endossar.

Para nossos propósitos, contudo, o importante é ressaltar que, contrariando a interpretação dos construtivistas, uma leitura dos dois artigos de Merton deixa abundantemente claro seu caráter de intervenção, de manifestação de uma postura engajada em defesa da ciência. Mais precisamente, em defesa da ciência de acordo com uma determinada concepção, que valoriza os traços essenciais da ciência moderna, sem entretanto, deixar de questionar o auto-entendimento da ciência predominante na época. É importante deixar isso claro para rechaçar as críticas que tacham Merton de positivista ou cientificista. Merton critica o auto-entendimento da ciência por contemplar apenas sua faceta de conhecimento puro, valioso como um fim em si mesmo, não assumindo responsabilidade pelas aplicações do conhecimento científico. Segundo ele, essa exaltação da ciência pura é parte de uma estratégia voltada para a preservação da autonomia da ciência, a qual, entretanto, fracassa em seus objetivos, uma vez que o público leigo não acompanha a comunidade científica na separação entre a ciência e suas aplicações, de forma que, quando essas são consideradas nefastas (como no caso, principalmente, das aplicações bélicas), a ciência é incluída entre os responsáveis e “a antipatia aos produtos tecnológicos é projetada sobre a própria ciência" (Merton, 1973a [1938], p. 261). Por outro lado, invocando o imperativo da responsabilidade social, Merton compara favoravelmente a reação dos cientistas ingleses à "prostituição do esforço científico para propósitos militares” com a apatia dos cientistas nos Estados Unidos, uma situação que, como o autor observa em uma nota posterior, mudou com o advento da bomba atômica (p. 262). 
Merton analisa várias "fontes de hostilidade" que ameaçam a ciência, porém o contexto deixa claro que a principal motivação para seu movimento de defesa foram as violações da autonomia cometidas pelos nazistas, com a introdução de critérios raciais na avaliação das teorias científicas e dos cientistas, que levavam a teoria da relatividade de Einstein a ser condenada por ser judaica, e ao expurgo, nas universidades e institutos de pesquisa, de cientistas não arianos. A análise mertoniana aplica-se com perfeição também ao caso Lysenko que, com certeza, só não foi mencionado nos artigos em pauta por ter tido seu desenlace, e ficado conhecido no Ocidente, cerca de uma década mais tarde, vindo depois a se tornar o símbolo por excelência dos desastres que podem advir de interferências políticas na ciência. ${ }^{21} \mathrm{O}$ que muda nos dois casos é apenas o caráter das interferências, que envolveram, no dos nazistas, critérios raciais, no dos soviéticos, critérios de classe, baseados na doutrina das duas ciências, a burguesa e a proletária, e no materialismo dialético, entendido como a filosofia do proletariado.

O conceito de éthos, portanto, não é fruto de um desenvolvimento interno da sociologia da ciência naturalista, mas uma reação a ameaças à autonomia da ciência, parte de um movimento, de natureza política, em defesa das tradições científicas. Seus participantes, incluindo Merton, sustentam os valores do éthos, não apenas discorrem sobre eles, transformado-os em fatos, como se faz na sociologia naturalista. A seguinte passagem deixa isso claro.

Ataques incipientes e reais à integridade da ciência levaram os cientistas a reconhecer sua dependência de tipos particulares de estrutura social. Manifestos e pronunciamentos de associações de cientistas tratam das relações entre a ciência e a sociedade. Uma instituição sob ataque precisa reexaminar suas fundações, reiterar seus objetivos, procurar sua razão de ser. A crise estimula a auto-avaliação. Agora, confrontados com ameaças a seu modo de vida, os cientistas foram dolorosamente lançados a um estado agudo de auto-consciência: consciência de si como um elemento integral da sociedade, com as respectivas obrigações e interesses. Uma torre de marfim torna-se insustentável quando seus muros ficam sob assalto prolongado. (...) [O enfrentamento da crise] levou a um esclarecimento e reafirmação do éthos da ciência moderna (Merton, 1973b [1942], p. 267-8).

21 Para um estudo que corrige as versões simplistas do caso Lysenko (cf. Lewontin \& Levin, 1976). A partir de 1953, com a morte de Stalin, o prestígio de Lysenko entrou em queda, suas ideias e métodos foram sendo progressivamente abandonados. Para uma crítica aos soviéticos por terem conduzido esse processo sem reconhecer (e refletir sobre) o erro cometido (cf. Lecourt, 1977). 
No último parágrafo de Merton (1973 [1938]), lê-se: "este artigo não apresenta um programa de ação para resistir a ameaças ao desenvolvimento e à autonomia da ciência", uma observação que, se, por um lado, limita o alcance do trabalho, por outro, não deixa dúvidas quanto a suas intenções, próprias de uma postura engajada. ${ }^{22}$

Evidências favoráveis a essa interpretação emergem do episódio seguinte no desenrolar da fortuna crítica das concepções mertonianas sobre o éthos. Depois do sucesso inicial, seguido de um período de descrédito resultante da crítica pós-moderna, elas são reabilitadas, não porém pela linhagem dominante na sociologia da ciência, mas por autores engajados, principalmente três dos críticos da mercantilização da ciência mencionados ao longo deste ensaio, a saber, Ziman, Krimsky e Lacey (cf. Garcia \& Martins, 2009).

O pioneiro foi Ziman, o físico teórico que, na segunda parte de sua carreira tornou-se um pensador da ciência. Em dois de seus livros mais importantes (cf. Ziman, 1994, 2000), ele expõe uma visão crítica das mudanças pelas quais as práticas científicas vêm passando, estruturada pelos conceitos de ciência acadêmica e ciência pós-acadêmica (grosso modo, equivalentes aos de CAO e ciência neoliberal, em nossa terminologia). Entre as características que distinguem essas duas formas de ciência encontra-se o éthos próprio de cada uma. O éthos da ciência acadêmica é o éthos mertoniano, formado pelos quatro imperativos institucionais, acrescidos da originalidade. Fazendo um trocadilho com a palavra grega $\kappa v \delta o \varsigma$, que significa glória, ou prestígio, e é também usada em inglês ( $k u d o s$ ), Ziman o simboliza com o acrônimo CUDOS (recapitulando: communism, universalism, desinterestedness, originality, scepticism). ${ }^{\mathbf{2} 3}$ Kudos é o que almejam os cientistas acadêmicos. Já a caracterização do éthos da ciência pós-acadêmica é feita por uma via indireta, passando pelo conceito de ciência industrial. O éthos da ciência industrial é composto pelas normas associadas aos seguintes atributos, por meio dos quais Ziman a descreve:

muito esquematicamente, a ciência industrial é “proprietária”24 (proprietary), local, autoritária, encomendada (commissioned), e especializada (expert). Ela pro-

22 Referindo-se a Merton (1973a), na introdução de uma coletânea de textos de Merton por eles organizada, Marcovich e Shinn reconhecem o caráter engajado do artigo, mas, ao mesmo tempo, o desmerecem, caracterizando-o como "um panfleto", uma "sucessão de afirmações e opiniões”, carente de evidências confirmadoras (cf. Merton, no prelo). 23 Na literatura posterior, o "o" de "CUDOS" costuma ser identificado com o "o" de "organized", em vez de com o "o" de "originality". Uma exceção é Kalleberg (2007b, p. 142), que segue Ziman ao incluir a originalidade, mas vai além acrescentando a humildade, e passando assim de CUDOS para CUDOSH.

24 "Proprietária", no sentido daquilo que pode ser objeto de propriedade. Para ser mercantilizado, um bem deve ter esse atributo, uma vez que a mercadoria pressupõe a troca, e a troca pressupõe a propriedade (privada). No caso dos conhecimentos científicos e tecnológicos, ser "proprietário" significa ser "protegido" pelos direitos de propriedade intelectual, pelos direitos autorais para o conhecimento científico, pelas patentes para o tecnológico. 
duz conhecimento "proprietário" que não necessariamente é dado a público. Tem seu foco em problemas técnicos locais, em vez de no entendimento geral. Pesquisadores industriais submetem-se à autoridade gerencial, em vez de agir como indivíduos. Sua pesquisa é encomendada, tendo em vista fins práticos, em vez de empreendida em busca do conhecimento. São empregados como solucionadores de problemas especializados, em vez de por sua criatividade pessoal (Ziman, 2000, p. 79).

As iniciais desses termos formam o acrônimo PLACE, "lugar", aquilo que se obtém fazendo boa ciência industrial. ${ }^{25}$ A ciência pós-acadêmica é definida em um registro dinâmico, como resultado de um processo de industrialização, que está em curso e provoca a substituição das normas mertonianas pelas da ciência industrial.

Krimsky (cf. 2003) é muito influenciado por Ziman, a quem cita abundantemente ao tratar do éthos mertoniano. Assim como Ziman, ele analisa as mudanças nas práticas científicas em termos de uma transição entre diferentes formas que a ciência assume, cada qual com seu éthos. Ao reportar as ideias de Ziman, Krimsky usa o termo “ciência pós-acadêmica", porém, ao falar em seu próprio nome, prefere "ciência no interesse privado". A ciência no interesse privado é contrastada não apenas com a ciência acadêmica, mas também com a forma que se põe como alternativa, a ciência no interesse público.

Lacey (2008), por sua vez, é influenciado por Krimsky, de quem toma emprestado o termo "ciência no interesse privado". Lacey avança na caracterização dessa forma dando ao éthos que lhe é próprio o nome de éthos científico-comercial, e submetendo-o a uma análise muito mais elaborada que a de Ziman. O conceito de autonomia individualista moderna figura nessa análise como um dos cinco conjuntos de teses das quais derivam as normas do éthos científico-comercial.

Em comum, Ziman, Krimsky e Lacey preservam o cerne do conceito de éthos, ainda que se afastem de Merton no que diz respeito à sua caracterização, isto é, aos valores e normas que o compõem. Lacey, em particular, ressalta a necessidade de acrescentar "às virtudes normalmente listadas no éthos científico, a virtude da tolerância em relação a uma multiplicidade de valores e da solidariedade para com os excluídos" (Lacey, 2008, p. 321). Com essa ressalva, pode-se dizer que nossos três autores sustentam as normas do éthos, e mobilizam-nas como fundamento de uma crítica à ciência neoliberal, e componente de uma ciência desmercantilizada, pós-neoliberal. Isso demonstra a vitalidade do conceito de éthos, quando corretamente entendido, isto é, não enquanto elemento de uma teoria no campo da sociologia da ciência naturalizada,

25 Seria melhor ainda se o acrônimo fosse "MONEY". 
mas como um recurso argumentativo na luta ideológico-política em torno da condução das práticas científicas. ${ }^{26}$

Em seus artigos, Merton traz à tona a semelhança entre a situação vivida por Galileu em seu conflito com a Igreja, e a dos cientistas de meados do século xx confrontados com as interferências políticas do Estado. A análise proposta a respeito da situação atual permite colocar como um terceiro episódio nessa sequência o solapamento do éthos, decorrente da mercantilização da ciência. Esquematicamente, o que muda de um episódio para outro são apenas a natureza e o agente das interferências, interferências religiosas, por parte da Igreja, políticas, por parte do Estado, econômicas, por parte do mercado. Nos dois primeiros episódios, a ciência saiu vitoriosa. O que acontecerá dessa vez depende do posicionamento da comunidade científica em relação aos processos mercantilizadores em curso. Essa perspectiva sugere que todos os cientistas e defensores da ciência, que ficariam do lado de Galileu contra a Igreja, e que se horrorizam com as interferências nazistas e o caso Lysenko, precisam, por dever de coerência, combater a submissão da ciência ao mercado promovida pelo neoliberalismo.

\section{Conclusão}

Os qualificativos "galileana" e "vannevariana" têm a vantagem de remeter à origem histórica das formas de autonomia que designam. Mas em certos contextos, tal como no desta conclusão - o mais adequado são termos que remetam, em vez de à origem, ao conteúdo das formas, àquilo que sua reivindicação implica. Nesse sentido, a autonomia galileana (levando em conta as observações acima segundo as quais o método é o elemento dominante na relação com o éthos) pode ser chamada autonomia metodológica. E a vannevariana, autonomia programática, uma vez que diz respeito aos rumos da pesquisa científica ou, em outras palavras, ao programa de pesquisa da ciência. A autonomia neoliberal não precisa de outro nome, pois o qualificativo remete tanto à localização na história, sendo de conhecimento geral que o neoliberalismo é um fenômeno da atualidade, quanto ao conteúdo da forma, caracterizada pelos princípios neoliberais do individualismo e da competitividade.

26 Entre outros autores que adotam a mesma estratégia, de criticar a mercantilização da ciência pelas violações do éthos que ela promove, encontram-se Kalleberg (cf. 2007b), Sztompka (cf. 2007), Radder (cf. 2010a), e Resnik (cf. 2010). Kalleberg (2007a) e Radder (2010a) mencionam outro vetor de recuperação do éthos mertoniano, a saber, o associado à onda de estabelecimento de códigos de ética para a pesquisa científica, que vem crescendo nas últimas décadas, podendo ser interpretada, pelo menos em parte, com uma reação da própria comunidade científica aos problemas causados pela mercantilização da ciência. 
Nesses termos, respondendo à pergunta colocada na introdução, podemos resumir as considerações da segunda parte deste ensaio dizendo que a forma de autonomia a ser reivindicada pela ciência hoje (1) exclui a autonomia neoliberal, (2) cede terreno na autonomia programática, mas (3) insiste na reivindicação da autonomia metodológica. Trata-se de uma forma inserida em um sistema democrático de condução da ciência que, como vimos, implica o exercício da responsabilidade social por parte dos cientistas. Dada a importância desse requisito, pode ser chamada autonomia com responsabilidade social, ou autonomia socialmente responsável. É a forma própria da ciência no interesse público ou ciência pós-neoliberal.

Agradecimentos. Uma versão parcial deste ensaio foi apresentada no iv Seminário de História e Filosofia da Ciência realizado em Ilhéus, em agosto de 2010; a versão completa, em abril de 2011, em um seminário do Projeto Temático "Gênese e Estrutura da Tecnociência". Pelos comentários e sugestões, agradeço aos participantes desses eventos, especialmente a Hugh Lacey e aos debatedores no seminário de Ilhéus, Alberto Cupani e Antonio Augusto Passos Videira, bem como a Isabel Loureiro.

\title{
Marcos Barbosa de Oliveira
}

Professor Associado da Faculdade de Educação, Universidade de São Paulo. Pesquisador Principal do Projeto Temático Fapesp o $7 / 5^{386} 7^{-0}$, Departamento de Filosofia, Universidade de São Paulo, Brasil. mbdolive@usp.br

\begin{abstract}
In the first part of this article, three forms that the autonomy of science has assumed in the course of its history are distinguished: the Galilean one, the Vannevarian one, and the neoliberal one. The Galilean form was claimed by Galileo in his conflict with the Catholic Church. The term "Vannevarian" comes from Vannevar Bush, responsible for the report, Science, the endless frontier, which played a crucial role in the configuration of scientific practices in the post World War II period. Vannevarian autonomy has to do with the directions of scientific research. Neoliberal autonomy consists in each scientist's freedom to search for funds for the research he intends to carry out from any source, public or private, in view only of his self-interest (intellectual or economic). In the second part of the article, the conceptual and historic frameworks provided by those distinctions are used to discuss the question: "what form of autonomy should be claimed by science today?" The procedure consists in determining, for each of the three forms, what should be maintained, and what should be abandoned. The conclusion arrived at is that neoliberal autonomy should be discarded, the Vannevarian one restricted, and the Galilean one preserved.
\end{abstract}

KeYwords • Autonomy of science. Galileo. Serendipity. Neoliberalism. Commodification. Innovation. Social responsibility in science. Scientific éthos. Merton. Conflict of interests. 


\section{REFERÊNGIAS BIBLIOGRÁFICAS}

Anderson, P. Balanço do neoliberalismo. In: Sader, E. \& Gentili, P. (Ed.). Pós neoliberalismo: as políticas sociais e o estado democrático. São Paulo: Paz e Terra, 1996. p. 9-21.

AngelL, M. The truth about the drug companies: how they deceive us and what to do about it. New York: Random House, 2004.

Applbaum, K. Marketing global health care: the practices of big pharma. In: Panitch, L. \& Leys, C. (Ed.). Morbid symptoms: health under capitalism. London: Merlin, 2009. p. 84-102.

BAKER, D. The reform of intellectual property. Post-Autistic Economics Review, 32, p. 2005. Disponível em: 〈http://www.paecon.net/PAEReview/issue32/Baker32.htm〉. Acesso em: 2 jan. 2011.

Barber, B. Science and the social order. New York: The Free Press, 1952.

Barnes, S. B. \& Dolby, R. G. A. The scientific ethos: a deviant viewpoint. European Journal of Philosophy, 11, p. 3-25, 1970.

Barnes, B. (Ed.). Sociology of science: selected readings. Harmondsworth: Penguin, 1972.

BELt, H. van DEN. Robert Merton, intellectual property, and open science: a sociological history for our times. In: RADDER, H. (Ed.). The commodification of academic research: science and the modern university. Pittsburgh: University of Pittsburgh Press, 2010. p. 187-230.

Brown, J. R. One-shot science. In: RADDER, H. (Ed.). The commodification of academic research: science and the modern university. Pittsburgh: University of Pittsburgh Press, 2010. p. 90-109.

Bush, V. Science, the endless frontier. Washington: National Science Foundation, 1990.

Butler, D. Lost in translation. Nature, 449, p. 158-9, 2007.

CARLotto, M. C. Ciência como instituição e como prática: a mudança do regime disciplinar/estatal de produção e difusão do conhecimento científico no Brasil vista a partir do Laboratório Nacional de Luz Síncroton. São Paulo, 2008. Dissertação (Mestrado em Sociologia). Faculdade de Filosofia, Letras e Ciências Humanas, Universidade de São Paulo.

CoLE, et al. Science the endless frontier: learning from the past, designing for the future. Columbia: University of Columbia, 1994-1996. Disponível em: <http://www.cspo.org/products/conferences/bush/ fulltexthighlights.pdf $>$. Acesso em: 31 ago. 2010.

Gruz, C. H. B. \& Ghaimovich, H. Brazil. In: Unesco science report 2010: the current status of science around the world. Paris: Unesco, 2010. p. 103-21.

Cupani, A. A propósito do "éthos" da ciência. Episteme, 3, 6, p. 16-38. 1998.

Dagnino, R. (Org.). Tecnologia social: ferramenta para construir outra sociedade. 2 ed. Campinas: Komedi, 2010. v. 1.

Dias, R. B. \& Novaes, H. T. Contribuições da economia da inovação para a reflexão acerca da tecnologia social. In: Dagnino, R. (Org.). Tecnologia social: ferramenta para construir outra sociedade. 2 ed. Campinas: Komedi, 2010. v. 1, p. 155-73.

Drahos, P. \& Braithwatte, J. Information feudalism: who owns the knowledge economy? New York: The New Press, 2003.

Fagerberg, J. Innovation: a guide to the literature. In: Fagerberg, J.; Mowery, D. C. \& Nelson, R. R. (Ed.). The Oxford handbook of innovation. New York: Oxford University Press, 2005· p. 1-26.

Fagerberg, J.; Mowery, D. C. \& Nelson, R. R. (Ed.). The Oxford handbook of innovation. New York: Oxford University Press, 2005.

Freeman, C. The economics of industrial innovation. Harmondsworth: Penguin Books, 1974.

Garcia, J. L. Tecnologia, mercado e bem-estar humano: para um questionamento do discurso da inovação. Alicerces: Revista de Investigação, Ciência e Tecnologia, e Artes, 3, 3, p. 19-31, 2010.

GARCiA, J. L. \& MARTIns, H. Oéthos da ciência e suas transformações contemporâneas, com especial atenção à biotecnologia. Scientiae Studia, 7, 1, p. 83-104, 2009. 
Gontijo, C. TRIPS: o acordo de propriedade intelectual. Brasília: INESG, 2003.

As transformações do sistema de patentes, da convenção de Paris ao acordo TRIPS. Brasília: Fundação Heinrich Böll, 2005.

Grant, B. Merck published fake journal. The Scientist, 3o/4/2009a. Disponível em: <http://www.thescientist.com/blog/display/55671/>. Acesso em: 2 fev. 2011.

Elsevier published 6 fake journals. The Scientist, $7 / 5 / 2009 \mathrm{~b}$. Disponível em: <http://www.thescientist.com/blog/display/55679/>. Acesso em: 2 fev. 2011.

Greenberg, D. S. Science, money, and politics: political triumph and ethical erosion. Chicago: University of Chicago Press, 2001.

Harvey, D. A brief history of neoliberalism. Oxford: Oxford University Press, 2007.

HAYeK, F. A. O caminho da servidão. 2 ed. Porto Alegre: Globo, 1977.

Hötтеске, D. \& Silva, C. C. Why implementing history and philosophy in school science education is a challenge: an analysis of obstacles. Science \& Education, 20, 3-4, p. 293-316, 2011.

Joss, S. Making technology accountable - citizen's conferences in the era of public accountability. Diacrítica, Filosofia e Cultura, 23, 2, p. 299-316, 2009. Disponível em: <http://ceh.ilch.uminho.pt/Diacr\% C3\%ADtica_Fil_23-2.pdf>. Acesso em: 2 jan. 2011.

Kalleberg, R. Robert K. Merton: a modern sociological classic. Journal of Classical Sociology, 7, 2, p. 1316, 2007a.

. A reconstruction of the ethos of science. Journal of Classical Sociology, 7, 2, p. 2007b. p. 137-60.

Kitcher, P. Science, truth, and democracy. Oxford: Oxford University Press, 2001.

KRIMSKr, S. Science in the private interest: has the lure of profits corrupted biomedical research? Oxford: Rowman \& Littlefield, 2003.

Lacey, H. Ciência, respeito à natureza e bem-estar humano. Scientiae Studia, 6, 3, p. 297-327, 2008.

Langley, C. \& Parkinson, S. Science and the corporate agenda: the detrimental effects of commercial influence on science and technology. Folkestone: Scientists for Global Responsibility, 2009. Disponível em: <http://www.sgr.org.uk/SciencePolicy/CorporateInfluence.html〉. Acesso em: 12 jun. 2010.

Lecourt, D. Proletarian science? : the case of Lysenko. London: NLB, 1977.

Lewontin, R. \& Levins, R. The problem of Lysenkoism. In: Rose, H. \& Rose, S. (Ed.). The radicalisation of science. London: The Macmillan Press, 1976. p. 32-64.

Loureiro, I.; Cevasco, M. E. \& Leite, J. C. (Org.). O espírito de Porto Alegre. São Paulo: Paz e Terra, 2002.

Mariconda, P. R. \& Lagey, H. Aáguia e os estorninhos: Galileu e a autonomia da ciência. Tempo Social, 13, 1, p. 49-65, 2001.

Matthews, M. R. Science teaching: the role of history and philosophy of science. New York: Routledge, 1994.

Merton, R. K. Social theory and social structure. Glencoe: The Free Press, 1949.

. The sociology of science: theoretical and empirical investigations. Chicago: University of Chicago Press, 1973. p. 286-324.

. Science and the social order. In: . The sociology of science: theoretical and empirical investigations. Chicago: University of Chicago Press, 1973a [1938].

. The normative structure of science. In:___. The sociology of science: theoretical and empirical investigations. Chicago: University of Chicago Press, 1973b [1942].

. Priorities in scientific discovery. In: __. The sociology of science: theoretical and empirical investigations. Chicago: University of Chicago Press, 1973c.

. Ensaios selecionados de sociologia da ciência. São Paulo: Associação Filosófica Scientiae Studia/Editora 34 . No prelo.

Merton, R. K. \& BARber, E. The travels and adventures of serendipity: a study in sociological semantics and the sociology of science. Princeton: Princeton University Press, 2006. 
Mitroff, I. The subjective side of science: a philosophical inquiry into the psychology of the Apollo moon scientists. Amsterdam: Elsevier, 1974.

Moyninan, D H. et al. Dossiê sobre a fabricação de doenças. PloS Medicine, 3, 4, p. 425-65, 2006.

Mulkay, M. J. Some aspects of cultural growth in the natural sciences. Social Research, 36, 1, p. 22-52, 1969.

Musschenga, A W. et al. The business of drug research: a mixed blessing. In: Radder, H. (Ed.). The commodification of academic research: science and the modern university. Pittsburgh: University of Pittsburgh Press, 2010. p. 110-31.

O’Connell, D. (Ed.). Dossie neglected diseases. Nature, 44, p. p. 157-82, 2007.

Oliveira, M. B. DE. Ciência: força produtiva ou mercadoria? Crítica Marxista, 21, p. 77-96, 2005.

. A avaliação neoliberal na Universidade e a responsabilidade social dos pesquisadores. Scientiae Studia, 6, 3, p. 379-87, 2008 .

Sobre o caráter quantitativo da avaliação neoliberal da Universidade. No prelo.

Panitch, L. \& Leys, C. (Ed.). Morbid symptoms: health under capitalism (Socialist Register 2010). London: Merlin, 2009.

Paulani, L. O projeto neoliberal para a sociedade brasileira: sua dinâmica e seus impasses. São Paulo: Boitempo, 2008. p. 105-39.

Ріттоск, A. B. Climate change: the science, impacts and solutions. London: Earthscan, 2009.

RADDER, H. (Ed.). The commodification of academic research: science and the modern university. Pittsburgh: University of Pittsburgh Press, 2010.

RADDER, H. Mertonian values, scientific norms, and the commodification of academic research. In: RADDER, H. (Ed.). The commodification of academic research: science and the modern university. Pittsburgh: University of Pittsburgh Press, 2010a. p. 231-58.

RESNIK, D. B. Financial interests and the norms of academic science. In: RAdDER, H. (Ed.). The commodification of academic research: science and the modern university. Pittsburgh: University of Pittsburgh Press, 2010. p. 65-89.

Rose, H. \& Rose, S. (Ed.). The radicalisation of science. London: The Macmillan Press, 1976.

Sader, E. \& Gentili, P. (Ed.). Pós neoliberalismo: as políticas sociais e o estado democrático. São Paulo: Paz e Terra, 1996.

SHARIF, N. Emergence and development of the national innovation systems concept. Research Policy, 35 , p. $745^{-66}, 2006$.

Shinn, T. \& Ragouet, P. Controvérsias sobre a ciência: por uma sociologia transversalista da atividade científica. São Paulo: Editora 34, 2008.

Sterckx, S. Knowledge transfer from academia to industry through patenting and licensing: rethoric and reality. In: RADDER, H. (Ed.). The commodification of academic research: science and the modern university. Pittsburgh: University of Pittsburgh Press, 2010. p. 44-64.

Stiglitz, J. E. Economic foundations of intellectual property rights. Duke Law Journal, 57, p. 101-32, 2008.

Sтокеs, D. Pasteur's quadrant: basic science and technological innovation. Washington: Brookings Institution Press, 1997 .

Storer, N. W. The social system of science. New York: Holt, Rinehart and Winston, 1966.

Szтом PкA, P. Trust in science: Robert K. Merton's inspirations. Journal of Classical Sociology, 7, 2, p. 21120,2007 .

Testart, J. Genética e controle cidadão. In: Loureiro, I.; Cevasco, M. E. \& Leite, J. C. (Org.). O espírito de Porto Alegre. São Paulo: Paz e Terra, 2002. p. 149-62.

Toren, N. The scientific ethos debate: a meta-theoretical view. Social Science \& Medicine, 17, 21, p. $1665^{-}$ $72,1983$.

UnESCO science report 2010: the current status of science around the world. Paris: Unesco, 2010. 
Formas DE AUTONOMIA DA GIÊNGIA

West, S. S. The ideology of academic scientists. Institute of Radio Engineers Transactions on Engineering Management, EM-7, 2, p. 54-62, 1972.

Ziman, J. Teaching and learning about science and society. Cambridge: Cambridge University Press, 1980.

Ziman, J. An introduction to science studies: the philosophical and social aspects of science and technology. Cambridge: Cambridge University Press, $19^{84}$.

. Prometheus bound: science in a dynamic steady state. Cambridge: Cambridge University Press, 1994. Of one mind: the collectivization of science. New York: AIP Press, 1995.

The social responsibility of scientists: basic principles. In: . Of one mind: the collectivization of science. New York: AIP Press, 1995a. p. 181-99.

Social responsibility in Victorian science. In:___ Of one mind: the collectivization of science. New York: AIP Press, 1995b. p. 200-24.

. Real science: what it is, and what it means. Cambridge: Cambridge University Press, 2000. 